This Health Hazard Evaluation (HHE) report and any recommendations made herein are for the specific facility evaluated and may not be universally applicable. Any recommendations made are not to be considered as final statements of NIOSH policy or of any agency or individual involved. Additional HHE reports are available at http://www.cdc.gov/niosh/hhe/reports

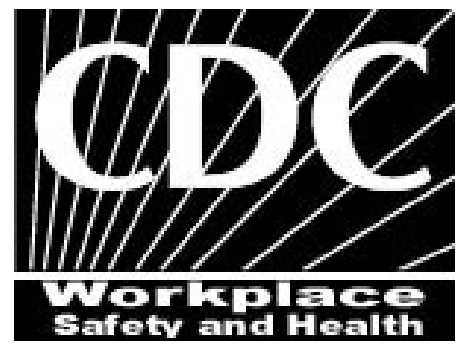

NIOSH HEALTH HAZARD EVALUATION REPORT:

HETA \#2002-0222-2879

Marion County Board of Education

Fairmont, West Virginia

\title{
July 2002
}

DEPARTMENT OF HEALTH AND HUMAN SERVICES

Centers for Disease Control and Prevention

National Institute for Occupational Safety and Health

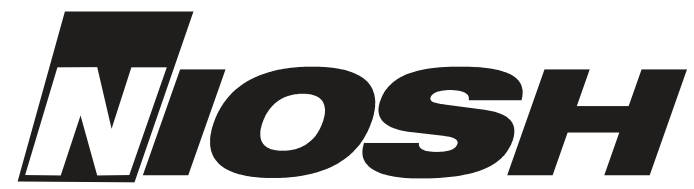


The Hazard Evaluations and Technical Assistance Branch (HETAB) of the National Institute for Occupational Safety and Health (NIOSH) conducts field investigations of possible health hazards in the workplace. These investigations are conducted under the authority of Section 20(a)(6) of the Occupational Safety and Health (OSHA) Act of 1970, 29 U.S.C. 669(a)(6) which authorizes the Secretary of Health and Human Services, following a written request from any employer or authorized representative of employees, to determine whether any substance normally found in the place of employment has potentially toxic effects in such concentrations as used or found.

HETAB also provides, upon request, technical and consultative assistance to Federal, State, and local agencies; labor; industry; and other groups or individuals to control occupational health hazards and to prevent related trauma and disease. Mention of company names or products does not constitute endorsement by NIOSH.

\title{
ACKNOWLEDGMENTS AND AVAILABILITY OF REPORT
}

This report was prepared by Randy L. Tubbs, Ph.D., of HETAB, Division of Surveillance, Hazard Evaluations and Field Studies (DSHEFS). Desktop publishing was performed by David Butler. Review and preparation for printing were performed by Penny Arthur.

Copies of this report have been sent to employee and management representatives at the Marion County Board of Education, the West Virginia Board of Education, and the OSHA Regional Office. This report is not copyrighted and may be freely reproduced. Single copies of this report will be available for a period of three years from the date of this report. To expedite your request, include a self-addressed mailing label along with your written request to:

\author{
NIOSH Publications Office \\ 4676 Columbia Parkway \\ Cincinnati, Ohio 45226 \\ 800-356-4674
}

After this time, copies may be purchased from the National Technical Information Service (NTIS) at 5825 Port Royal Road, Springfield, Virginia 22161. Information regarding the NTIS stock number may be obtained from the NIOSH Publications Office at the Cincinnati address.

For the purpose of informing affected employees, copies of this report shall be posted by the employer in a prominent place accessible to the employees for a period of 30 calendar days. 


\section{Highlights of the NIOSH Health Hazard Evaluation}

\section{Evaluation of Diesel Engine Noise Exposures for School Bus Operators at the Marion Co. Board of Education}

NIOSH investigators were requested to conduct an evaluation of school bus drivers' noise exposures to see if they could suffer hearing losses due to exposures on the job. The drivers felt that the flat-nosed transit bus with the engine next to the driver's seat was producing too much noise.

\section{What NIOSH Did}

- We measured noise levels over the entire day on eight buses. Six of the buses were transit-style and two were conventional style. One of the transit buses had its diesel engine in the rear of the bus.

- We talked to employees and Transportation Department representatives on their concerns about bus noise.

- We kept an activity log for one of the buses over the entire work day.

\section{What NIOSH Found}

- Noise levels were low enough so that there is little risk for hearing loss from your job.

- The transit-style buses were generally noisier than the conventional-style buses.

- Communications between the bus driver and riders were difficult when the bus was moving.

\section{What Marion County Board of} Education Managers Can Do

- Maintain the buses so that rattles and leaks do not add to the noise levels in the buses.

- Begin a formal reporting program where drivers can report noticeable increases in noise levels in their buses.

- Purchase new vehicles with the quietest noise specifications.

- Suggest that the State's Department of Education lower the noise requirements to improve communication conditions for the drivers.

What the Marion County Board of Education Employees Can Do

- Report changes in noise levels to the Transportation Department. 


\title{
Health Hazard Evaluation Report 2002-0222-2879 Marion County Board of Education \\ Fairmont, West Virginia July 2002
}

\author{
Randy L. Tubbs, Ph.D.
}

\section{SUMMARY}

The National Institute for Occupational Safety and Health (NIOSH) was requested to evaluate noise levels in the interior of school buses operated by the Marion County Board of Education in West Virginia. Drivers were particularly concerned about the transit-style buses that have a flat front where the diesel engine is behind the windshield next to the driver's seat, covered by a cowling. A NIOSH investigator performed a one-day survey of the noise levels in six buses with the transit-style configuration as well as two conventional-style buses with the diesel engine in front of the windshield, under a hood. The NIOSH investigator rode one of the buses for the entire day as the driver picked up and dropped off students at school and home making a log of activities to match with the noise data for that bus.

The noise levels were measured with noise dosimeters placed in the bus with the microphone taped to the right side of the driver's seat at approximately the level of the driver's ear. The overall daily average noise was compared to three different evaluation criteria for increased risk of occupational hearing loss from workplace noise exposures. The measured noise levels for all eight buses were less than the limits set forth in the criteria, with none of the levels greater than 82 decibels on an A-weighted scale expressed as a time-weighted average. The conventional-style buses were generally found to be quieter than the transit-style buses.

The time-weighted average noise levels measured in this evaluation were less than all the of the evaluation criteria referenced in this report. The school bus operators are not at increased risk for occupational noise-induced hearing loss from exposure to bus engine noise. Some general recommendations to maintain low noise levels in the buses and to possibly lead to additional noise reductions are offered at the end of the report.

Keywords: SIC 4151 (School Buses), noise, school bus driver, diesel engine, dosimetry 


\section{TABLE OF CONTENTS}

Preface

Acknowledgments and Availability of Report $\ldots \ldots \ldots \ldots \ldots \ldots \ldots \ldots \ldots \ldots \ldots \ldots \ldots \ldots \ldots \ldots \ldots$

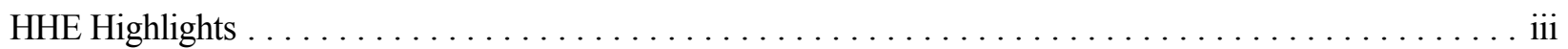

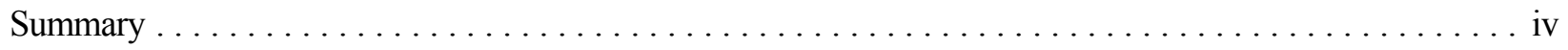

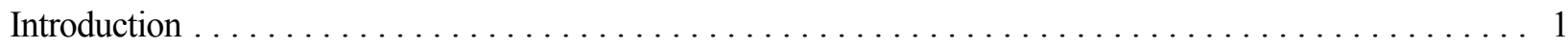

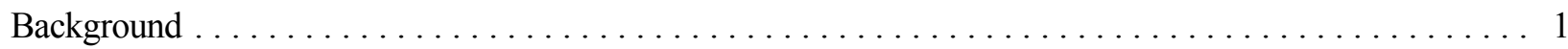

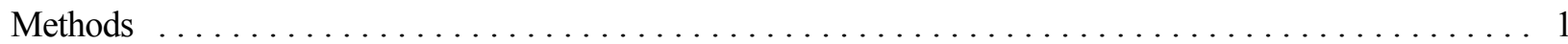

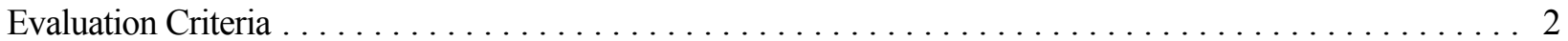

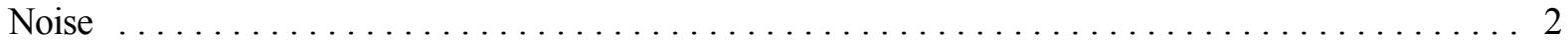

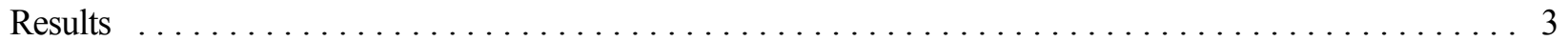

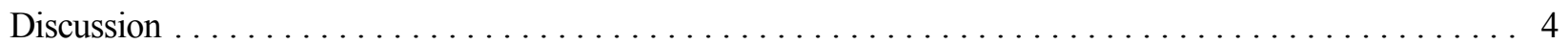

Conclusions $\ldots \ldots \ldots \ldots \ldots \ldots \ldots \ldots \ldots \ldots \ldots \ldots \ldots \ldots \ldots \ldots \ldots \ldots \ldots \ldots \ldots \ldots$

Recommendations ...................................... 4

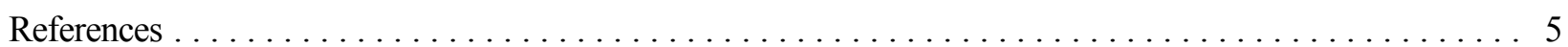




\section{INTRODUCTION}

The National Institute for Occupational Safety and Health (NIOSH) received a request for a health hazard evaluation (HHE) from school bus operators at the Marion County Board of Education in Fairmont, West Virginia, on April 15, 2002. The bus drivers were concerned about the noise levels in the school buses produced by the vehicles' diesel engines. In particular, the drivers felt that the transitstyle, flat-nosed buses were the loudest at the driver's seat.

On April 23-24, 2002, a NIOSH investigator visited the Marion County Board of Education Transportation Department office in Fairmont. An opening conference was held on the first day of the site visit where it was decided to place noise meters in several of the buses the following day. The meters were in a bus for the entire day while students were transported to and from school and noise readings were made at the driver's seat. The NIOSH investigator rode one of the buses for the entire day recording times when the bus was transporting students.

\section{BACKGROUND}

The Marion County School District is composed of 24 elementary and secondary schools. The Transportation Department is responsible for transporting nearly 8900 students to and from these schools. There are 79 bus operators driving buses on the 79 school routes. The department has nine buses that are designated as spares. Buses are purchased to meet the West Virginia Minimum Requirements for Design and Equipment of School Buses dictated by the West Virginia Department of Education. ${ }^{1}$ The requirement for noise levels inside the vehicle is a maximum of 85 decibels on the A-weighted [dB(A)] scale. The test procedure, outlined in the National Minimum Standards for School Buses, requires that $\mathrm{dB}(\mathrm{A})$ noise measurements be made 6 " to the right of the driver's seat in line with his or her ear while the engine is accelerated to its maximum governed speed with the transmission in neutral gear.
Two different styles of buses are used by the Marion County Board of Education. The conventional-style bus has an engine compartment at the front of the bus covered by a hood that is in front of the windshield. The driver sits behind the engine compartment's firewall. The second style of bus is the transit configuration. The front of the bus is flat with the engine located behind the bus's front grill and windshield. A cowling that covers the engine compartment is located next to the driver's seat on the center line of the bus. The board also has transitstyle buses where the engine has been placed at the rear of the vehicle. Engines in all buses are dieselpowered. The Transportation Department parks their buses at two locations, one in the city of Fairmont at the bus maintenance garage and the other at North Marion High School in Farmington, West Virginia.

\section{METHODS}

To measure the time-weighted average (TWA) noise levels, Quest ${ }^{\circledR}$ Electronics Model Q-300 Noise Dosimeters were placed in a pouch behind the school bus operator's seat in the early morning before the drivers arrived. The dosimeter microphones were attached to the right side of the seat with duct tape at approximately the level of the driver's ear. The dosimeters were left on the bus for the entire day. For the bus parked at the high school bus lot, the NIOSH investigator spent the day riding along and writing down times when the bus was transporting students and when it was parked. At the end of the day, the dosimeters from buses at the Fairmont bus yard were removed by a Transportation Department employee and the time when this occurred was recorded. These dosimeters were collected by the NIOSH investigator later in the day after the routes had been completed and were then placed in the pause mode. The noise information was downloaded to a personal computer for interpretation with QuestSuite for Windows ${ }^{\circledR}$ computer software. The dosimeters were calibrated before and after the work shift according to the manufacturer's instructions. 
EVALUATION CRITERIA

As a guide to the evaluation of the hazards posed by workplace exposures, NIOSH field staff employ environmental evaluation criteria for the assessment of a number of chemical and physical agents. These criteria are intended to suggest levels of exposure to which most workers may be exposed up to 10 hours per day, 40 hours per week for a working lifetime without experiencing adverse health effects. It is, however, important to note that not all workers will be protected from adverse health effects even though their exposures are maintained below these levels. A small percentage may experience adverse health effects because of individual susceptibility, a preexisting medical condition, and/or a hypersensitivity (allergy). In addition, some hazardous substances may act in combination with other workplace exposures, the general environment, or with medications or personal habits of the worker to produce health effects even if the occupational exposures are controlled at the level set by the criterion. These combined effects are often not considered in the evaluation criteria. Also, some substances are absorbed by direct contact with the skin and mucous membranes, and thus potentially increases the overall exposure. Finally, evaluation criteria may change over the years as new information on the toxic effects of an agent become available.

The primary sources of environmental evaluation criteria for the workplace are: (1) NIOSH Recommended Exposure Limits (RELs), ${ }^{2}$ (2) the American Conference of Governmental Industrial Hygienists' $\left(\mathrm{ACGIH}^{\circledR}\right)$ Threshold Limit Values $\left(\mathrm{TLVs}^{\circledR}\right),{ }^{3}$ and (3) the U.S. Department of Labor, Occupational Safety and Health Administration (OSHA) Permissible Exposure Limits (PELs). ${ }^{4}$ Employers are encouraged to follow the OSHA limits, the NIOSH RELs, the ACGIH TLVs, or whichever are the more protective criterion.

OSHA requires an employer to furnish employees a place of employment that is free from recognized hazards that are causing or are likely to cause death or serious physical harm [Occupational Safety and
Health Act of 1970, Public Law 91-596, sec. 5(a)(1)]. Thus, employers should understand that not all hazardous chemicals have specific OSHA exposure limits such as PELs and short-term exposure limits (STELs). An employer is still required by OSHA to protect their employees from hazards, even in the absence of a specific OSHA PEL.

A TWA exposure refers to the average airborne concentration of a substance during a normal 8- to 10-hour workday. Some substances have recommended STEL or ceiling values which are intended to supplement the TWA where there are recognized toxic effects from higher exposures over the short-term.

\section{Noise}

Noise-induced loss of hearing is an irreversible, sensorineural condition that progresses with exposure. Although hearing ability declines with age (presbycusis) in all populations, exposure to noise produces hearing loss greater than that resulting from the natural aging process. This noise-induced loss is caused by damage to nerve cells of the inner ear (cochlea) and, unlike some conductive hearing disorders, cannot be treated medically. ${ }^{5}$ While loss of hearing may result from a single exposure to a very brief impulse noise or explosion, such traumatic losses are rare. In most cases, noise-induced hearing loss is insidious. Typically, it begins to develop at 4000 or $6000 \mathrm{~Hz}$ (the hearing range is $20 \mathrm{~Hz}$ to $20000 \mathrm{~Hz}$ ) and spreads to lower and higher frequencies. Often, material impairment has occurred before the condition is clearly recognized. Such impairment is usually severe enough to permanently affect a person's ability to hear and understand speech under everyday conditions. Although the primary frequencies of human speech range from $200 \mathrm{~Hz}$ to $2000 \mathrm{~Hz}$, research has shown that the consonant sounds, which enable people to distinguish words such as "fish" from "fist," have still higher frequency components. ${ }^{6}$

The A-weighted decibel $[\mathrm{dB}(\mathrm{A})]$ is the preferred unit for measuring sound levels to assess worker noise exposures. The $\mathrm{dB}(\mathrm{A})$ scale is weighted to 
approximate the sensory response of the human ear to sound frequencies near the threshold of hearing. The decibel unit is dimensionless, and represents the logarithmic relationship of the measured sound pressure level to an arbitrary reference sound pressure (20 micropascals, the normal threshold of human hearing at a frequency of $1000 \mathrm{~Hz}$ ). Decibel units are used because of the very large range of sound pressure levels which are audible to the human ear. Because the $\mathrm{dB}(\mathrm{A})$ scale is logarithmic, increases of $3 \mathrm{~dB}(\mathrm{~A}), 10 \mathrm{~dB}(\mathrm{~A})$, and $20 \mathrm{~dB}(\mathrm{~A})$ represent a doubling, tenfold increase, and 100-fold increase of sound energy, respectively. It should be noted that noise exposures expressed in decibels cannot be averaged by taking the simple arithmetic mean.

The OSHA standard for occupational exposure to noise (29 CFR 1910.95) ${ }^{7}$ specifies a maximum PEL of $90 \mathrm{~dB}(\mathrm{~A})$ for a duration of 8 hours per day. The regulation, in calculating the PEL, uses a $5 \mathrm{~dB}$ time/intensity trading relationship, or exchange rate. This means that a person may be exposed to noise levels of $95 \mathrm{~dB}(\mathrm{~A})$ for no more than 4 hours, to 100 $\mathrm{dB}(\mathrm{A})$ for 2 hours, etc. Conversely, up to 16 hours exposure to $85 \mathrm{~dB}(\mathrm{~A})$ is allowed by this exchange rate. The duration and sound level intensities can be combined in order to calculate a worker's daily noise dose according to the formula:

$$
\text { Dose }=100 \mathrm{X}(\mathrm{C} 1 / \mathrm{T} 1+\mathrm{C} 2 / \mathrm{T} 2+\ldots+\mathrm{Cn} / \mathrm{Tn}),
$$

where $\mathrm{Cn}$ indicates the total time of exposure at a specific noise level and $\mathrm{Tn}$ indicates the reference duration for that level as given in Table G-16a of the OSHA noise regulation. During any 24-hour period, a worker is allowed up to $100 \%$ of his daily noise dose. Doses greater than $100 \%$ are in excess of the OSHA PEL.

The OSHA regulation has an additional action level (AL) of $85 \mathrm{~dB}(\mathrm{~A})$; an employer shall administer a continuing, effective hearing conservation program when the 8-hour time-weighted average (TWA) value exceeds the AL. The program must include monitoring, employee notification, observation, audiometric testing, hearing protectors, training, and record keeping. All of these requirements are included in 29 CFR 1910.95, paragraphs (c) through (o). Finally, the OSHA noise standard states that when workers are exposed to noise levels in excess of the OSHA PEL of $90 \mathrm{~dB}(\mathrm{~A})$, feasible engineering or administrative controls shall be implemented to reduce the workers' exposure levels.

NIOSH, in its Criteria for a Recommended Standard, ${ }^{8}$ and the ACGIH, ${ }^{3}$ propose exposure criteria of $85 \mathrm{~dB}(\mathrm{~A})$ as a TWA for 8 hours, $5 \mathrm{~dB}$ less than the OSHA standard. The criteria also use a more conservative $3 \mathrm{~dB}$ time/intensity trading relationship in calculating exposure limits. Thus, a worker can be exposed to $85 \mathrm{~dB}(\mathrm{~A})$ for 8 hours, but to no more than $88 \mathrm{~dB}(\mathrm{~A})$ for 4 hours or $91 \mathrm{~dB}(\mathrm{~A})$ for 2 hours. Twelve hours exposures have to be 83 $\mathrm{dB}(\mathrm{A})$ or less according to the NIOSH REL.

\section{RESULTS}

The Quest dosimeters collect data in a manner that allows one to directly compare the information with the three different noise criteria used in this survey, the OSHA PEL and AL, and the NIOSH REL. The OSHA criteria use a $90 \mathrm{~dB}(\mathrm{~A})$ criterion and $5 \mathrm{~dB}$ exchange rate for both the PEL and AL. The difference between the two is the threshold level employed, with a $90 \mathrm{~dB}(\mathrm{~A})$ threshold for the PEL and an $80 \mathrm{~dB}(\mathrm{~A})$ threshold for the AL. The threshold level is the lower limit of noise values included in the calculation of the criteria; values less than the threshold are ignored by the dosimeter. The NIOSH criterion differs from OSHA in that the NIOSH criterion is $85 \mathrm{~dB}(\mathrm{~A})$, the threshold is 80 $\mathrm{dB}(\mathrm{A})$, and it uses a $3 \mathrm{~dB}$ exchange rate.

Eight buses were surveyed with noise dosimeters during the evaluation. Six buses were transit-style and two were the conventional style. One of the transit buses had its engine in the rear. Data were collected according to the two OSHA and the NIOSH environmental evaluation criteria. Only noise data collected up to the time when the Transportation Department employee removed the dosimeter from the bus were included in the TWA analysis. The results are presented in Table 1. Noise 
levels measured on the eight buses were below all of the evaluation criteria. When compared to the most protective NIOSH criterion, none of the buses exceeded $82 \mathrm{~dB}(\mathrm{~A})$ for the work day, $3 \mathrm{~dB}$ less than the REL.

Minute-by-minute plots of the $\mathrm{dB}(\mathrm{A})$ values recorded on each bus are graphically shown in Figures 1-8. Figure 1 also includes the activity log for bus \#83 collected by the NIOSH investigator while riding the vehicle. The graphs show that the eight buses made either two or three runs per day. When the morning runs are compared for each of the eight buses, the following average noise levels were measured. For the transit-style buses, $\# 29$ was $83.2 \mathrm{~dB}(\mathrm{~A}), \# 70$ was $80.7 \mathrm{~dB}(\mathrm{~A})$, \#83 was $80.5 \mathrm{~dB}(\mathrm{~A})$, \#88 was 79.0 $\mathrm{dB}(\mathrm{A}), \# 90$ was $78.6 \mathrm{~dB}(\mathrm{~A})$, and \#102 (the rear engine vehicle) was $76.5 \mathrm{~dB}(\mathrm{~A})$. For the conventional-style buses, \#22 was $78.5 \mathrm{~dB}(\mathrm{~A})$ and \#92 was $76.3 \mathrm{~dB}(\mathrm{~A})$.

\section{Discussion}

Noise levels in none of the eight Marion County Board of Education school buses evaluated exceeded the environmental evaluation criteria for occupational noise exposure used in this report. Generally, the conventional-style buses and the rear engine transit-style bus were found to be quieter than the transit-style bus. However, for all buses, the TWA values for the entire day and the average noise levels measured when the bus was operating do not pose an increased risk for hearing loss to the bus operators from these occupational exposures.

The evaluation criteria referenced in this report are based on protecting employees' hearing. For the bus operators, a secondary concern is communication with the students and on the bus's mobile radio. Communication between the NIOSH investigator and the operator of the bus was difficult when the bus was driven and the investigator sat directly behind the driver. Several conversations had to be repeated throughout the day between these two individuals. Approximate $\mathrm{dB}(\mathrm{A})$ noise levels in work spaces where "just acceptable" speech and telephone communications are required is recommended to be between 58 and $68 \mathrm{~dB}(\mathrm{~A}){ }^{9}$ The buses were $8-15$ $\mathrm{dB}(\mathrm{A})$ above this recommended noise level which may be a partial explanation for the communication problems observed during the evaluation.

\section{CONCLUSIONS}

The bus operators employed by the Marion County Board of Education are not at an increased risk for occupational hearing loss as a result of driving students to and from school. The TWA noise levels were at least $3 \mathrm{~dB}(\mathrm{~A})$ below the most protective evaluation criterion referenced in this report. ${ }^{8}$ However, the noise levels measured while the buses were operating were found to present potential communication problems for the drivers with their students and with the mobile radio.

The West Virginia Department of Education has set a not to exceed level of $85 \mathrm{~dB}(\mathrm{~A})$ for noise at the bus operator's ear. ${ }^{1}$ At this level, it would be possible for a school bus operator to be exposed to noise that can cause hearing loss if the exposure were constant for more than eight hours a day for a working lifetime. Realistically, these drivers do not drive the vehicles for the entire 10-11 hour shifts that were observed in this evaluation. However, it might be prudent for the West Virginia Department of Education to research bus suppliers to see if the minimum requirement for noise levels at the operator's ear could be lowered $3-5 \mathrm{~dB}(\mathrm{~A})$ without adding significant expense to the vehicles.

\section{RECOMMENDATIONS}

Based on the measurements and observations made in the evaluation of noise exposure for Marion County Board of Education school bus operators, the following recommendations are made to improve working conditions for the employees.

1. School buses should be maintained to meet the state's minimum requirements for noise. Attention should focused on loose bus parts and worn window, door, and engine cowling seals 
that will increase noise levels in the interior of the buses.

2. A system for drivers to report perceived increases in noise levels in their vehicles should be formalized. A written record of the complaint and the steps taken to evaluate the complaint and alleviate any problems should provide data for future purchases and periodic maintenance schedules.

3. The rear-engine design and the conventionalstyle buses seem to offer lower noise levels for the bus driver. These styles of vehicles should be considered in future purchases.

4. The West Virginia Department of Education should re-evaluate its minimum requirements for interior noise in the bus emanating from the engine. The current requirement is set at the NIOSH recommended exposure limit to reduce the risk of occupational hearing loss in workers. Any exposures that would just exceed this limit because of a slight increase in noise intensity or workdays that are greater than 8 hours may put the drivers at increased risk for occupational hearing loss. A better strategy would be to set the noise levels $3-5 \mathrm{~dB}(\mathrm{~A})$ below the health risk criterion.

\section{REFERENCES}

1. Board of Education [2002]. West Virginia minimum requirements for design and equipment of school buses. Charleston, WV: West Virginia Board of Education, Title 126, Legislative Rule, Series 89, Policy 4334.

2. NIOSH [1992]. Recommendations for occupational safety and health: compendium of policy documents and statements. Cincinnati, $\mathrm{OH}$ : U.S. Department of Health and Human Services, Public Health Service, Centers for Disease Control and Prevention, National Institute for Occupational Safety and Health, DHHS (NIOSH) Publication No. 92-100.
3. ACGIH [2002]. $2002 \mathrm{TLVs}^{\circledR}$ and BEIs ${ }^{\circledR}$ : threshold limit values for chemical substances and physical agents and biological exposure indices. Cincinnati, OH: American Conference of Governmental Industrial Hygienists.

4. Code of Federal Regulations [1997]. 29 CFR 1910.1000. Washington, DC: U.S. Government Printing Office, Federal Register.

5. Ward WD, Royster LH, Royster JD [2000]. Anatomy \& physiology of the ear: normal and damaged hearing. Chapter 4. In: Berger EH, Royster LH, Royster JD, Driscoll DP, \& Layne M, eds. The noise manual. 5th ed. Fairfax, VA: American Industrial Hygiene Association, pp 101-122.

6. Suter AH [1978]. The ability of mildly hearing-impaired individuals to discriminate speech in noise. Washington, DC: U.S. Environmental Protection Agency, Joint EPA/USAF study, EPA 550/9-78-100, AMRL-TR-78-4.

7. CFR [1992]. 29 CFR 1910.95. Washington, DC: U.S. Government Printing Office, Federal Register.

8. NIOSH [1998]. Criteria for a recommended standard: occupational noise exposure (revised criteria 1998). Cincinnati, OH: U.S. Department of Health and Human Services, Centers for Disease Control and Prevention, National Institute for Occupational Safety and Health, DHHS (NIOSH) Publication No. 98-126.

9. Beranek LL [1988]. Criteria for noise and vibration in communities, buildings, and vehicles. In: Beranek LL, ed. Noise and Vibration Control. Rev. ed. Cambridge, Massachusetts: Institute of Noise Control Engineering, pp. 554-623. 
Figure 1

Marion County Board of Education

HETA 2002-0222

Fairmont, West Virginia

April 24, 2002

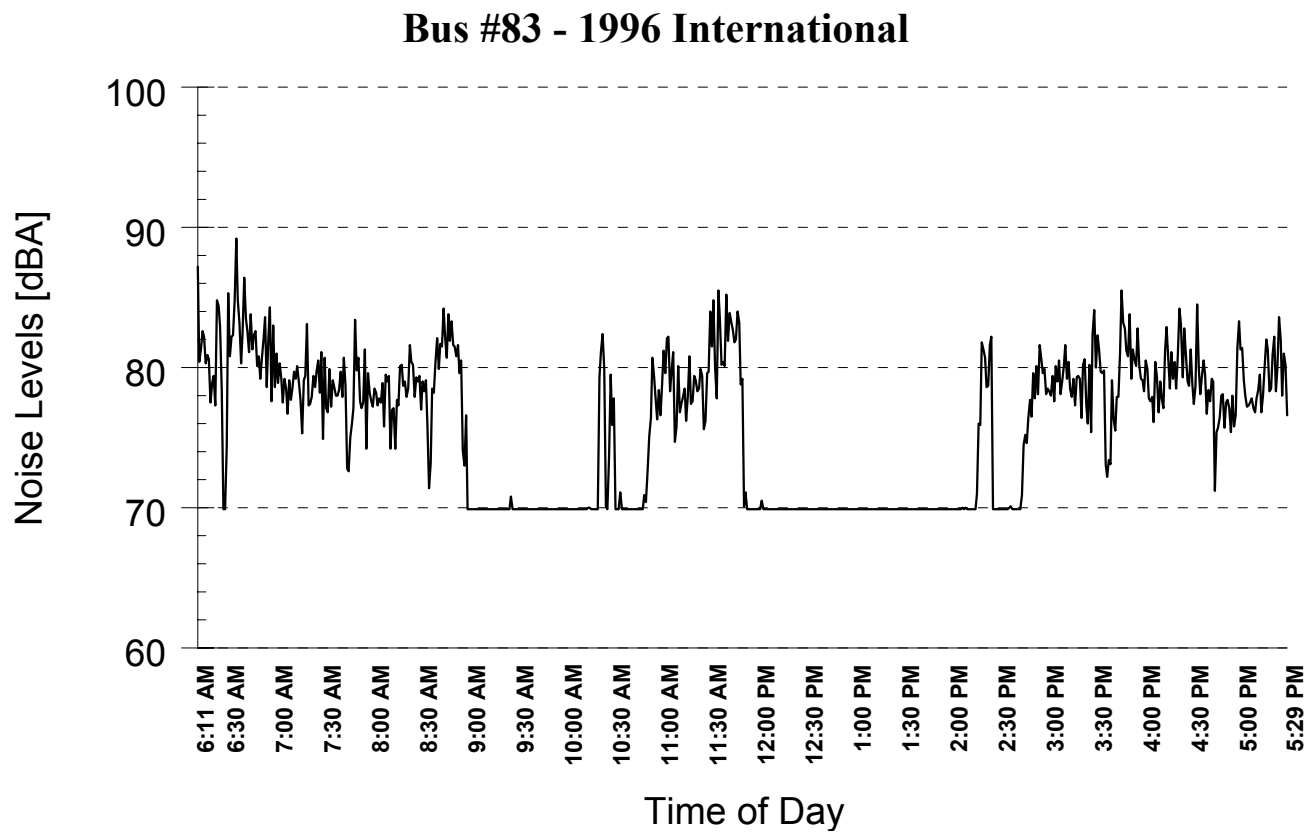

Activity Log for Transit-style Bus \#83

\begin{tabular}{|l|l||l|l|}
\hline \multicolumn{1}{|c|}{ Time } & \multicolumn{1}{c|}{ Activity } & \multicolumn{1}{c|}{ Time } & \multicolumn{1}{c|}{ Activity } \\
\hline 0615 & Left HS lot for fuel & 1152 & Return to HS lot; engine off \\
\hline 0627 & At fuel depot; engine off & $1417-1425$ & $\begin{array}{l}\text { Bus moved from HS lot to school; } \\
\text { engine off }\end{array}$ \\
\hline 0631 & Fueling complete; begin bus run & 1447 & Engine on; left school with children \\
\hline $0705-0730$ & Pick up children at bus stops & $1505-1525$ & Left HS to drop children at bus stops \\
\hline 0735 & Drop children at school & 1535 & At elementary school; idling \\
\hline 0745 & Bus parked; idling & $1543-1621$ & $\begin{array}{l}\text { Left school to drop children at bus } \\
\text { stops }\end{array}$ \\
\hline $0753-0825$ & Pick up children at bus stops & 1638 & Arrive at athletic field in Fairmont \\
\hline 0833 & Drop children at school & $1640-1710$ & Drop children at bus stops \\
\hline $0855-0859$ & Return to HS lot; engine off & 1730 & Return to HS lot; end of day \\
\hline 1055 & Left HS lot; begin bus run & & \\
\hline
\end{tabular}


Figure 2

Marion County Board of Education

HETA 2002-0222

Fairmont, West Virginia

April 24, 2002

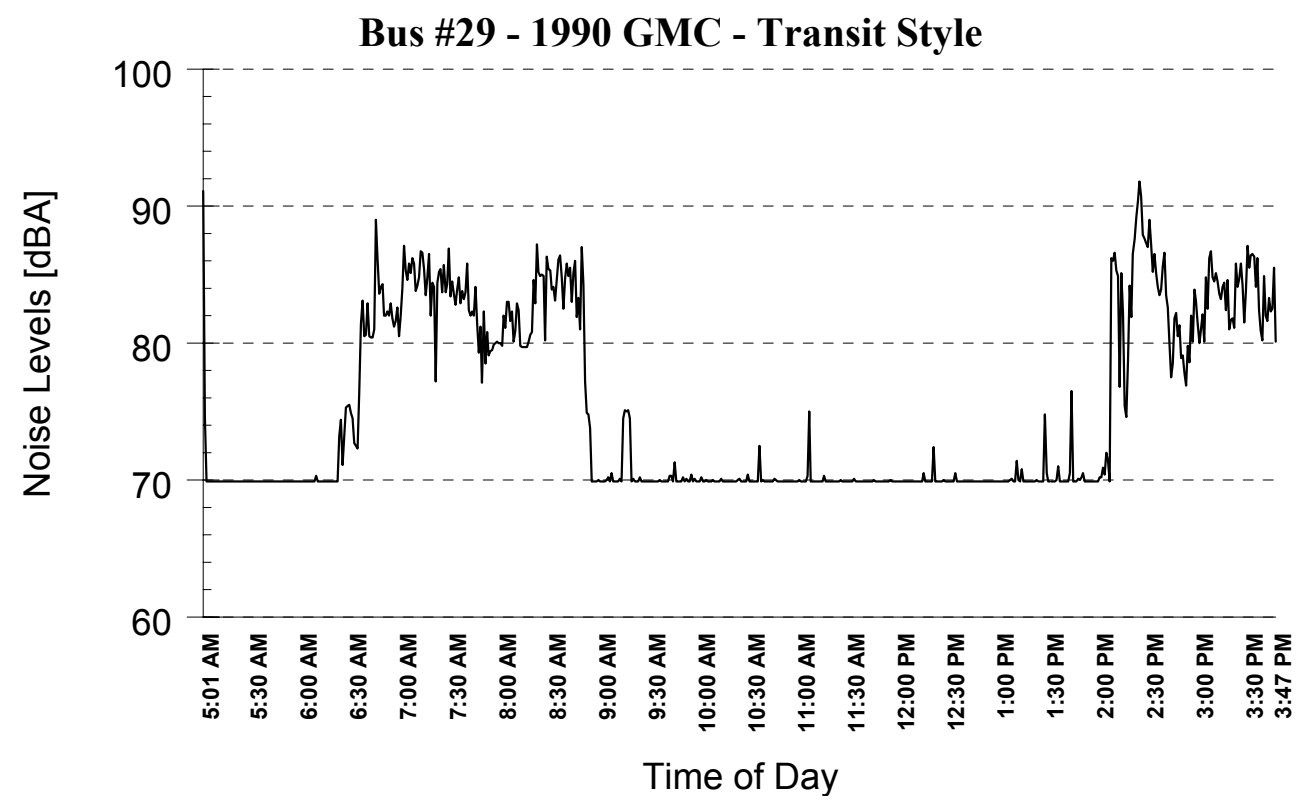

Figure 3

Marion County Board of Education

HETA 2002-0222

Fairmont, West Virginia

April 24, 2002

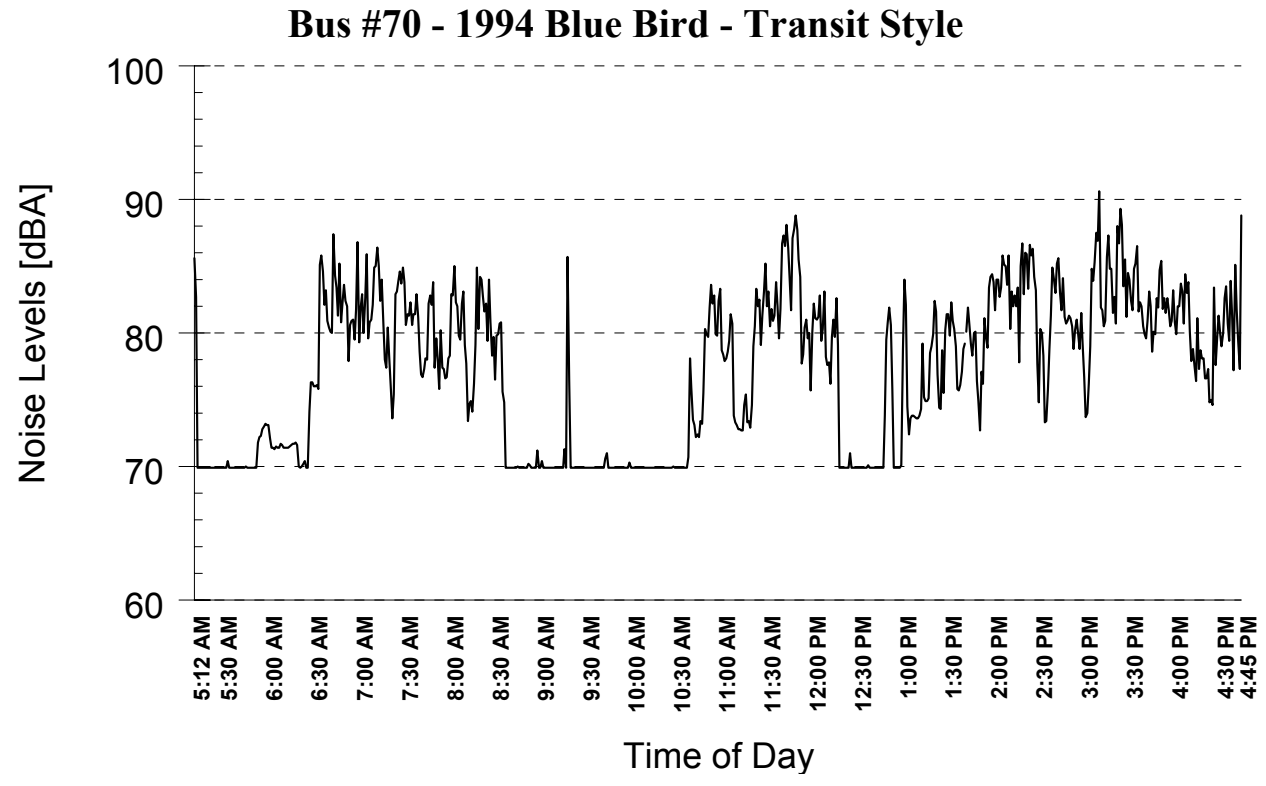


Figure 4

Marion County Board of Education

HETA 2002-0222

Fairmont, West Virginia

April 24, 2002

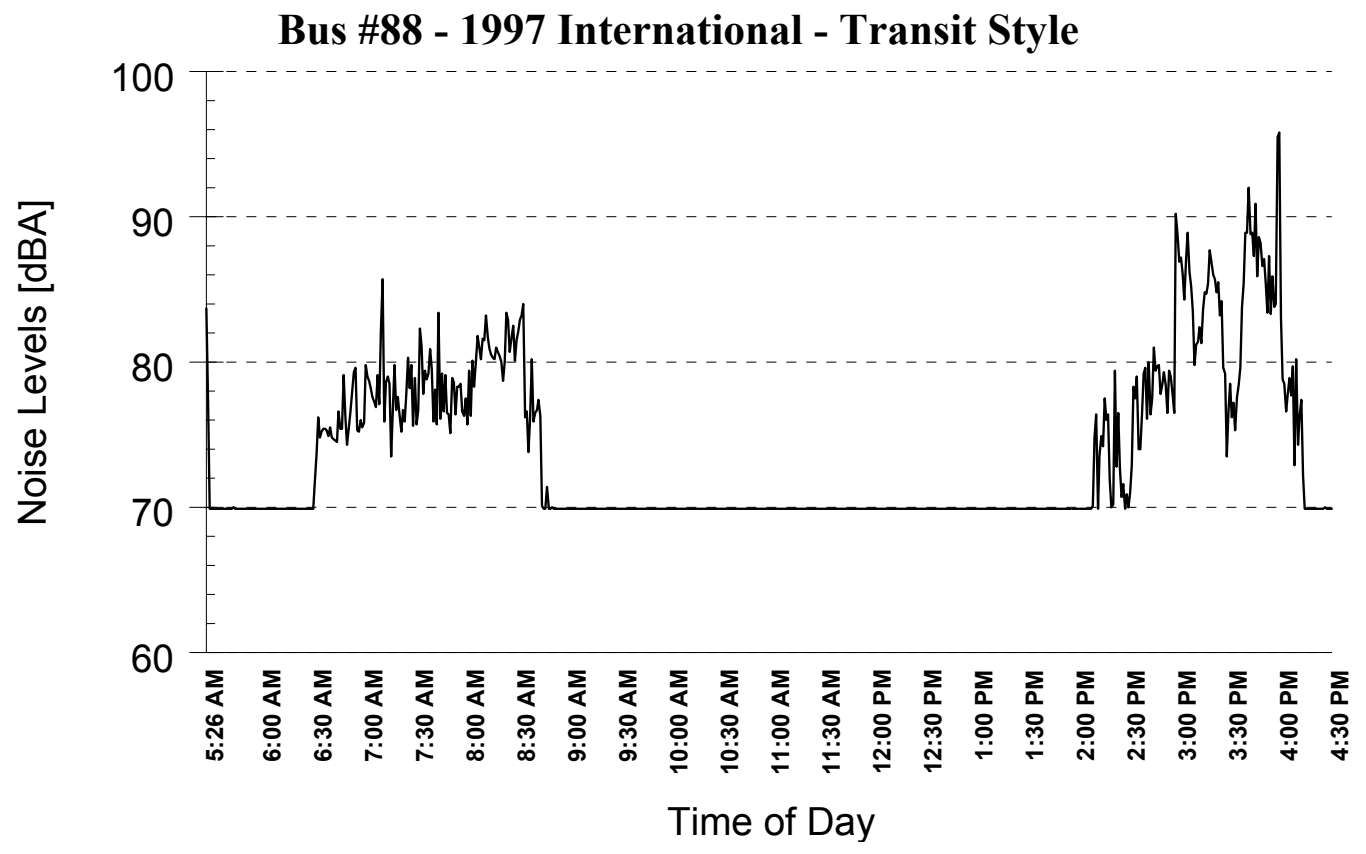

5

Marion County Board of Education

HETA 2002-0222

Fairmont, West Virginia

Figure

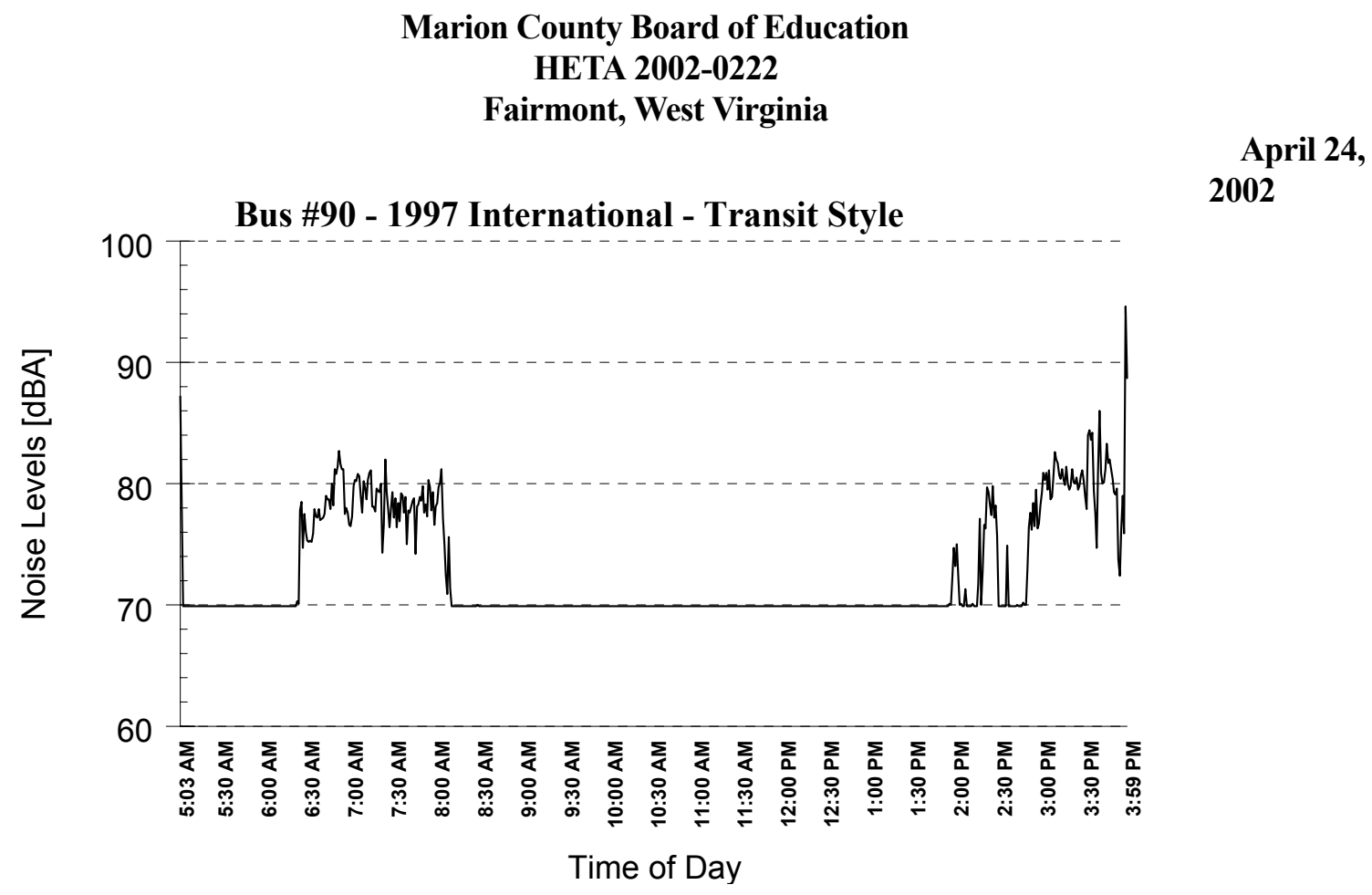


Figure 6

Marion County Board of Education

HETA 2002-0222

Fairmont, West Virginia

April 24, 2002

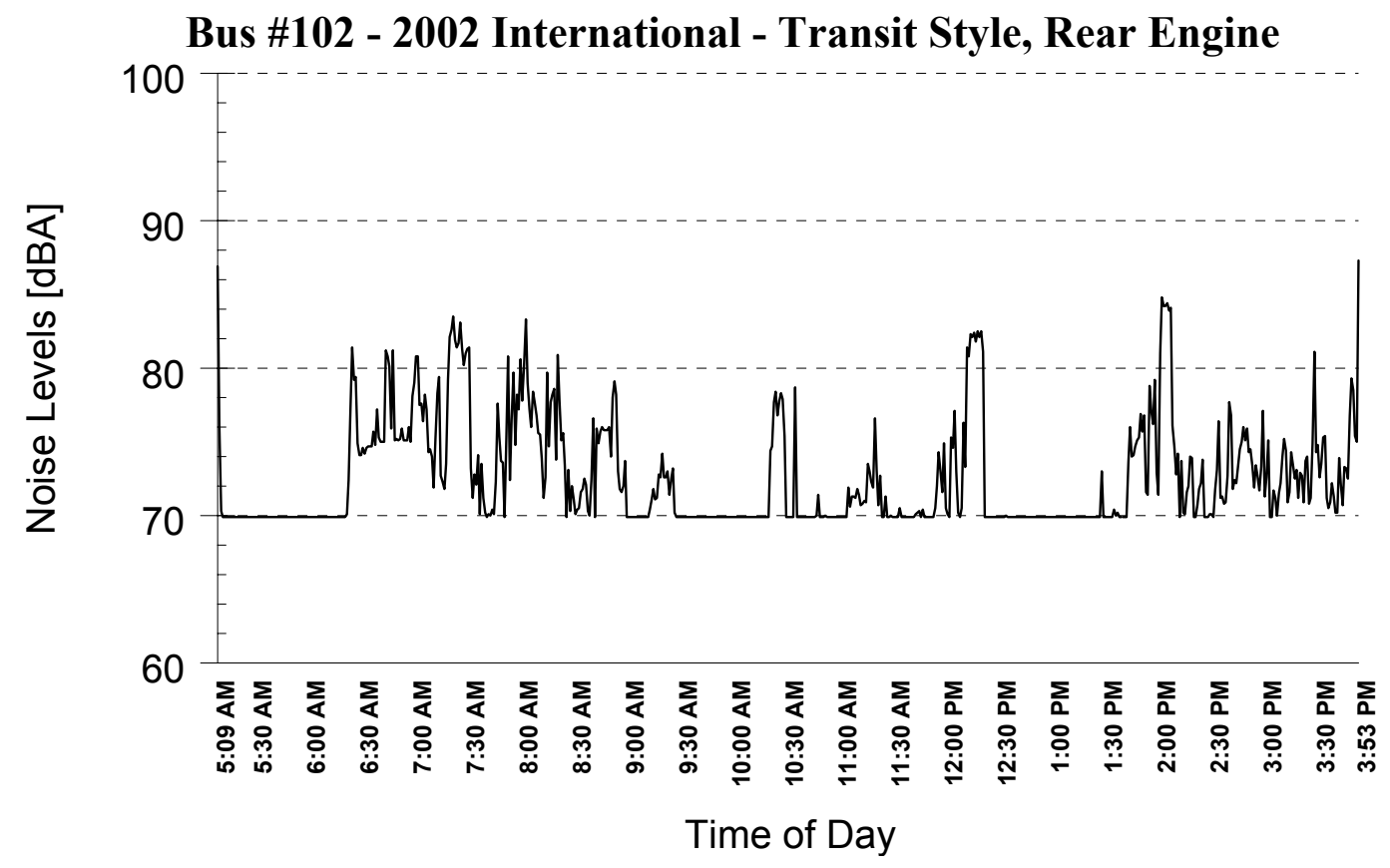

Figure 7

Marion County Board of Education

HETA 2002-0222

Fairmont, West Virginia

April 24, 2002

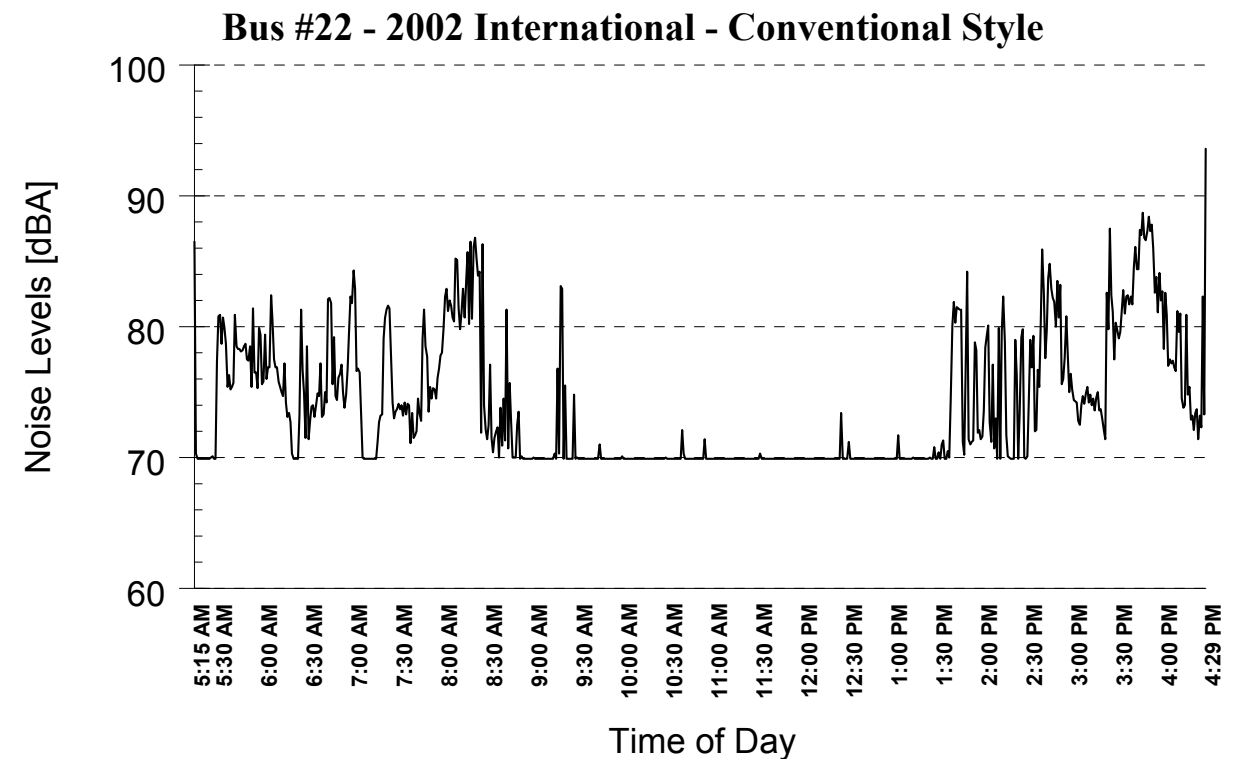


Figure 8

Marion County Board of Education

HETA 2002-0222

Fairmont, West Virginia

April 24, 2002

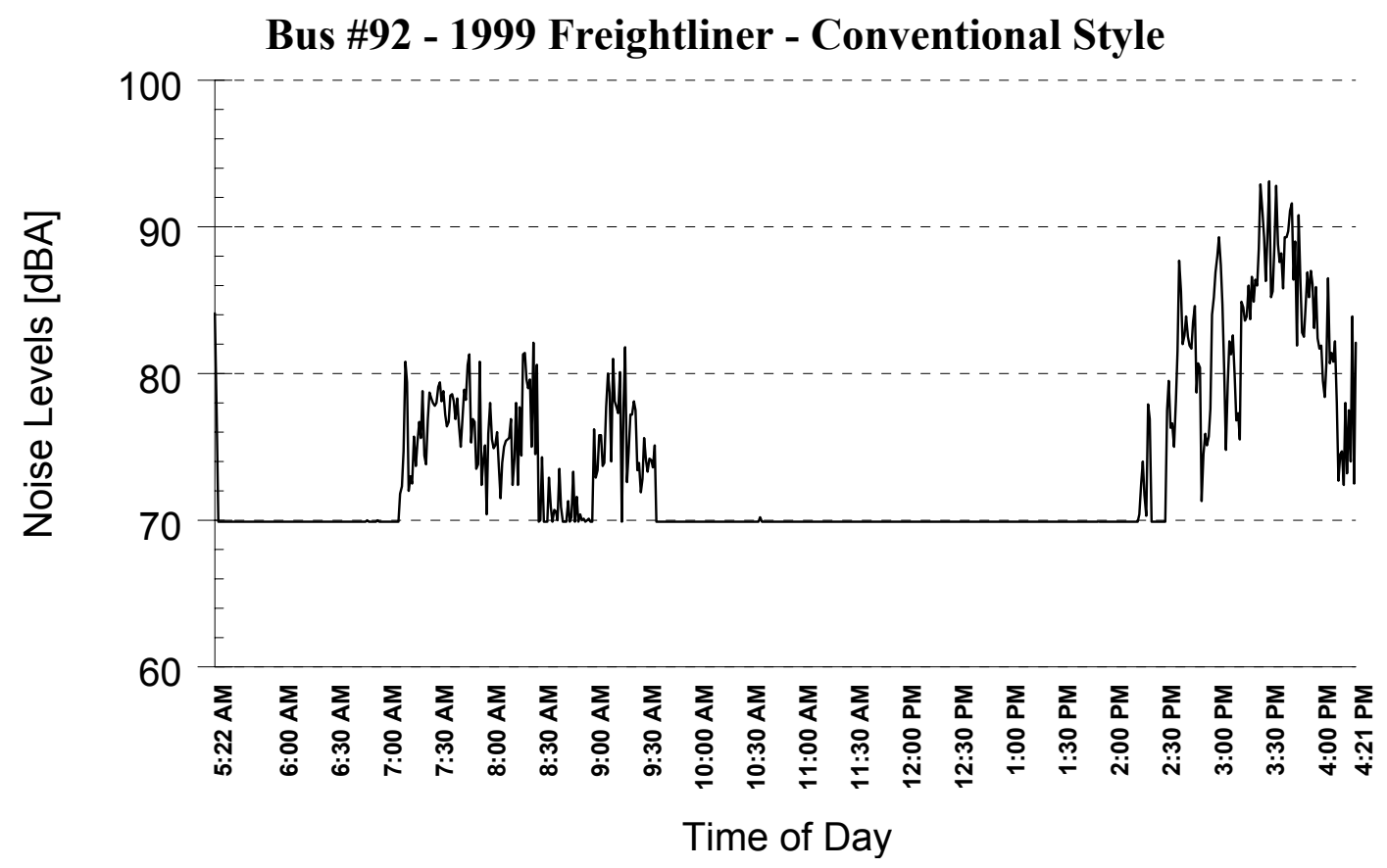


Table 1

Noise Dosimeter Results

Marion County Board of Education

HETA 2002-0222

Fairmont, West Virginia

April 24, 2002

\begin{tabular}{|c|c|c|c|c|c|c|c|c|}
\hline & & & OSH & PEL & OSI & & NIOS & REL \\
\hline Bus \# & Style & $\begin{array}{c}\text { Run } \\
\text { Time } \\
\text { [hh:mm] }\end{array}$ & \% Dose & TWA & \% Dose & TWA & \% Dose & TWA \\
\hline 29 & Transit & $10: 47$ & 1.4 & 59.3 & 16.3 & 76.9 & 43.6 & 81.4 \\
\hline 70 & Transit & $11: 34$ & 1.5 & 59.7 & 20.0 & 78.4 & 49.4 & 81.9 \\
\hline 83 & Transit & $11: 19$ & 0.5 & 52.2 & 10.8 & 73.9 & 29.7 & 79.7 \\
\hline 88 & Transit & $11: 05$ & 2.1 & 62.1 & 8.8 & 72.5 & 32.1 & 80.1 \\
\hline 90 & Transit & $10: 56$ & 0.2 & 46.8 & 3.9 & 66.6 & 15.8 & 77.0 \\
\hline 102 & $\begin{array}{c}\text { Transit - Rear } \\
\text { Engine }\end{array}$ & $10: 45$ & 0.1 & 41.6 & 3.4 & 65.5 & 13.0 & 76.1 \\
\hline 22 & Conventional & $11: 14$ & 1.0 & 56.4 & 7.8 & 71.6 & 24.5 & 78.9 \\
\hline 92 & Conventional & $10: 59$ & 2.7 & 63.9 & 9.2 & 72.8 & 32.4 & 80.1 \\
\hline
\end{tabular}


DEPARTMENT OF HEALTH AND HUMAN SERVICES

Centers for Disease Control and Prevention

National Institute for Occupational Safety and Health

4676 Columbia Parkway

Cincinnati, OH 45226-1998

\section{OFFICIAL BUSINESS}

Penalty for private use $\$ 300$

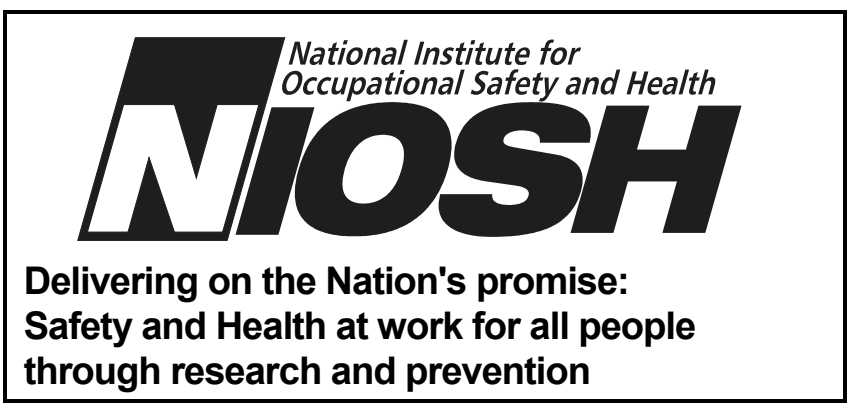

To receive NIOSH documents or information about occupational Safety and Health topics contact $\mathrm{NIOSH}$ at:

1-800-35-NIOSH (356-4674) Fax:

1-513-533-8573 E-mail: pubstaft@cdc.gov

or visit the NIOSH web site at:

www.cdc.gov/niosh/homepage.html

SAFER • HEALTHIER • PEOPLETM 